\title{
CONEXÕES ENTRE IMAGEM FOTOGRÁFICA E MEMÓRIA SOCIAL DO GARIMPO
}

\author{
Carlos de Matos Bandeira Junior (1) $\square$
}

Universidade Federal do Oeste do Pará I Santarém - PA - Brasil

Rubens Elias da Silva (ID $\triangle$

Universidade Federal do Oeste do Pará I Santarém - PA - Brasil 


\section{INTRODUÇÃO}

A garimpagem de ouro faz parte de um importante capítulo da história da Amazônia. A atual fase de expansão da exploração deste minério na região iniciou-se nos anos finais da década de 1950, estando diretamente associada a descobertas de jazidas ricas em minério na região do rio Tapajós e indiretamente relacionada com a política de ocupação da Amazônia, fomentada pelo planejamento governamental, realizado por meio da intervenção do Estado sobre a economia e sobre o território (Cleary 1992; Marthis 1995). De acordo com Becker (2004), esse processo toma corpo ainda no governo de Getúlio Vargas, com o programa "Marcha para Oeste”, a criação da Fundação Brasil Central e a implementação do Programa de Desenvolvimento para Amazônia. As políticas desenvolvimentistas ganham pujança no governo de Juscelino Kubitschek, no qual ações efetivas impactaram a região com investimentos em energia e com a construção de uma malha rodoviária de integração regional, como a abertura das rodovias Belém-Brasília e BrasíliaAcre. Essas políticas tiveram seguimento nas ações dos governos militares.

Em razão de não terem levado em consideração as especificidades da população e seus processos históricos, as políticas implementadas sobre a Amazônia brasileira produziram conflitos, impactos ambientais e não proporcionaram condições dignas de vida, tanto para as populações locais quanto para as pessoas que vieram para a região por meio de processos migratórios. Essa ineficácia deixou milhares de trabalhadores inseguros diante de um contexto de baixíssima absorção de mão de obra, em um cenário em que não havia infraestrutura mínima para a comercialização da produção agrícola. Todos esses elementos contribuíram para o direcionamento dessas pessoas a outros modos de produção, a fim de garantir o próprio desenvolvimento (Salomão 1984:54).

Nesse ponto, a garimpagem de ouro adquiriu papel fundamental na atração de mão de obra e, com o tempo, tornou-se uma frente de expansão autônoma na atração de trabalhadores. Cleary (1992) aponta que um dos elementos para que a garimpagem fosse vista como um modo de produção de grande interesse é a capacidade que a exploração aurífera, baseada na informalidade, possui de movimentar vultosa cifra financeira. Durante o período de 1986 a 1989 foram extraídas 46 toneladas de ouro da região do Tapajós, que, nesse momento, se tornou a maior produtora do país (Mathis 1995).

Toda essa pujança financeira proporcionada pela garimpagem teve grande papel no processo de ocupação demográfica da Amazônia, atraindo pessoas de diferentes partes do Brasil, principalmente da região Nordeste, dos estados da Bahia, do Ceará, do Piauí e do Maranhão, histórias que guardavam em comum o projeto pessoal e coletivo de melhorar de vida. Neste período, a população garimpeira presente na região amazônica foi estimada em torno de 200 mil pessoas, sem contar com os familiares (mulher e filhos) que acompanhavam o homem na sua jornada migratória (Cleary 1992:10).

O relato do ex-garimpeiro Jacinto, de 67 anos, oriundo da cidade de Timbira, no Maranhão, 
expressa o modo como ocorreu seu ingresso nesta empreitada: "[...] apareciam uns vizinhos que trabalhavam no garimpo e faziam aquela fofoca de que o garimpo era muito bom, ganhavase muito dinheiro". Nas palavras dele, os outros garimpeiros faziam "fofoca", retornavam às suas localidades com vestimentas distintas, cordões de ouro e externando os benefícios resultantes de se trabalhar nesses espaços. Aos que permaneciam (na maioria das vezes, agricultores familiares), essas impressões eram convites para também buscarem desenvolver tal atividade e, consequentemente, melhorar a vida.

Mesmo que esta atividade represente aspecto significativo para a compreensão a respeito das relações econômicas, culturais e populacionais da Amazônia, pesquisas sobre a temática ainda são escassas. Nesse sentido, o presente estudo vislumbra constituir uma história sensível (Bosi 2003), amparada nas fotografias, nas lembranças, nas narrativas, enfim, na memória social coletiva (Halbwachs 1968) de garimpeiros, atores sociais que vivenciaram as sociabilidades nos diversos contextos dos garimpos da região, trazendo à baila as subjetividades, as emoções e os silêncios das experiências individuais que se conectam ao universo social desses agentes.

\section{FOTOGRAFIA COMO NARRATIVA DE EXPERIÊNCIAS SOCIAIS}

Este ensaio ${ }^{1}$, composto por fotografias produzidas pelo pesquisador Carlos de Matos
Bandeira Junior e principalmente oriundas de acervo pessoal dos interlocutores (Figuras 1 a 10), propõe-se a refletir sobre as conexões entre a imagem fotográfica e o processo de constituição de memória coletiva (Halbwachs 1968), articulada por ex-garimpeiros acerca do trabalho e da cotidianidade das relações elaboradas nos garimpos de ouro da região amazônica, sobretudo os da área do Tapajós, com grande efervescência entre as décadas de 1970 e 1980 e onde esses agentes vivenciaram essas experiências em várias etapas da vida.

Por se tratar predominantemente de fotos organizadas em álbuns de família, as imagens podem ser pensadas na perspectiva proposta por Miriam Lifchit Moreira Leite (1993), ao buscar interpretar os significados e os conteúdos culturais contidos nelas, e conectados ao processo de memória dos personagens retratados, ou no contexto evidenciado pelas fotos. Leite (1993) defende esse entrelaçamento justamente pelo caráter fragmentário e descontínuo da fotografia, pois considera que, apesar de a imagem comunicar de modo excelente os sentimentos e as percepções, ela peca ao transmitir as redes de relacionamentos que fogem à capacidade comunicativa das suas dimensões espaciais. Portanto, se não houver uma descrição verbal do contexto da imagem, a fotografia pode ser um elemento mudo e ambíguo (Leite 1993:148).

A conexão entre a produção de discurso e o universo icônico da imagem funciona como

1 As imagens que compõem este ensaio fotográfico fazem parte de uma pesquisa de mestrado em curso no Programa de Pós-Graduação em Ciências da Sociedade da Universidade Federal do Oeste do Pará (PPGCS/UFOPA) e foram permitidas pelos interlocutores do estudo, com a devida ciência, para fins acadêmicos. 
gatilho de memória (Teixeira 2014) para o agente, que, a partir da visualidade da fotografia, é capaz de evocar lembranças e emoções sociais, como a saudade de situações vividas, as quais podem ser encurtadas entre um tempo passado e o tempo presente (Koury 2014).

Nas narrativas produzidas pelos garimpeiros, nas quais contaram suas histórias por meio de posse de fotografias do tempo do garimpo, as reminiscências emergiram de forma mais profunda e detalhada. Lembravam-se das minúcias cotidianas, do fotógrafo que capturou a imagem, dos amigos falecidos e de histórias de outros que nunca mais viram. Surgiram explicações sobre os equipamentos de trabalho, as técnicas para ser um bom garimpeiro e também descrições dos espaços e de vivências. Percebeu-se que uma gama de memórias já esquecidas foi disparada pela materialização proporcionada pela fotografia, dando possibilidades ao etnógrafo de atrelar as narrativas dos agentes, seus imaginários, aos discursos das camadas de significação contidas na imagem.

Para além do campo icônico da imagem, podemos tecer reflexões históricas e também observações relativas ao ato fotográfico, capturado por um filtro cultural (o autor), estabelecido em um espaço/tempo específico (Kossoy 2001). Portanto, a narrativa fotográfica sobre o garimpo possibilita-nos realizar uma comunicação das paisagens, das construções corporais dos atores fotografados, das técnicas e das tecnologias empregadas pelos personagens, a exemplo do autor das imagens, e das seleções do olhar na realidade representada.
Nesse sentido, é possível tomar a linguagem visual da fotografia como artefato cultural, com capacidade comunicacional de despertar nos leitores amplas conexões imaginárias em relação às variadas dimensões morais, sociais e estéticas contidas na realidade fotográfica (Koury 1999) e, no caso deste estudo, na realidade dos garimpos da região amazônica.

As fotografias apresentadas neste ensaio são utilizadas como meio de reavivar a memória dos ex-garimpeiros e, por meio da consciência discursiva (Giddens 2003), elaboram discursos onde se apresentam as dimensões contextuais e os espaços temporais de cada imagem, fornecendo-nos subsídios para embasar as leituras interpretativas dessas fotografias e traçar conexões mais amplas sobre as práticas sociais garimpeiras.

\section{REFERÊNCIAS}

Becker, B. K. 2004. Amazônia: geopolítica na virada do III milênio. Rio de Janeiro: Editora Garamond.

Bosi, E. 2003. O tempo vivo da memória: ensaios de psicologia social. São Paulo: Ateliê Editorial.

Cleary, D. 1992. A garimpagem de ouro na Amazônia: uma abordagem antropológica. Rio de Janeiro: UFRJ.

Giddens, A. 2003. A constituição da sociedade. São Paulo: Martins Fontes.

Halbwachs, M. 1968. A memória coletiva; traduzido do francês La memorie collective. Tradução de Laurent Léon Schffter. 2. ed. Paris: Press Uniersitaries de France. 
Kossoy, B. 2001. Fotografia \& história. São Paulo: Ateliê Editorial.

Koury, M. G. P. 1999. A imagem nas ciências sociais do Brasil: um balanço crítico. Revista Brasileira de Informação Bibliográfica em Ciências Sociais-BIB(47):49-63.

Koury, M. G. P. 2014. Estilos de vida e individualidade: escritos em antropologia e sociologia das emoções. Curitiba: Appris.

Leite, M. M. 1993. Retratos de família: leitura da fotografia histórica. São Paulo: Edusp.
Mathis, A. 1995. Garimpagem de ouro na Amazônia. Belém: Universidade Federal do Pará, Núcleo de Altos Estudos Amazônicos-NAEA.

Salomão, E. P. 1984. O ofício e a condição de garimpar, in Em busca do Ouro. Editado por G. A. Rocha, pp. 35-86. Rio de Janeiro: Marco Zero.

Teixeira, J. O. 2014. A proposta metodológica da fotografia como disparadora do gatilho da memória: aplicação à história de Telêmaco Borba-PR (1950-1969). Discursos Fotográficos 10(16):275-276. 


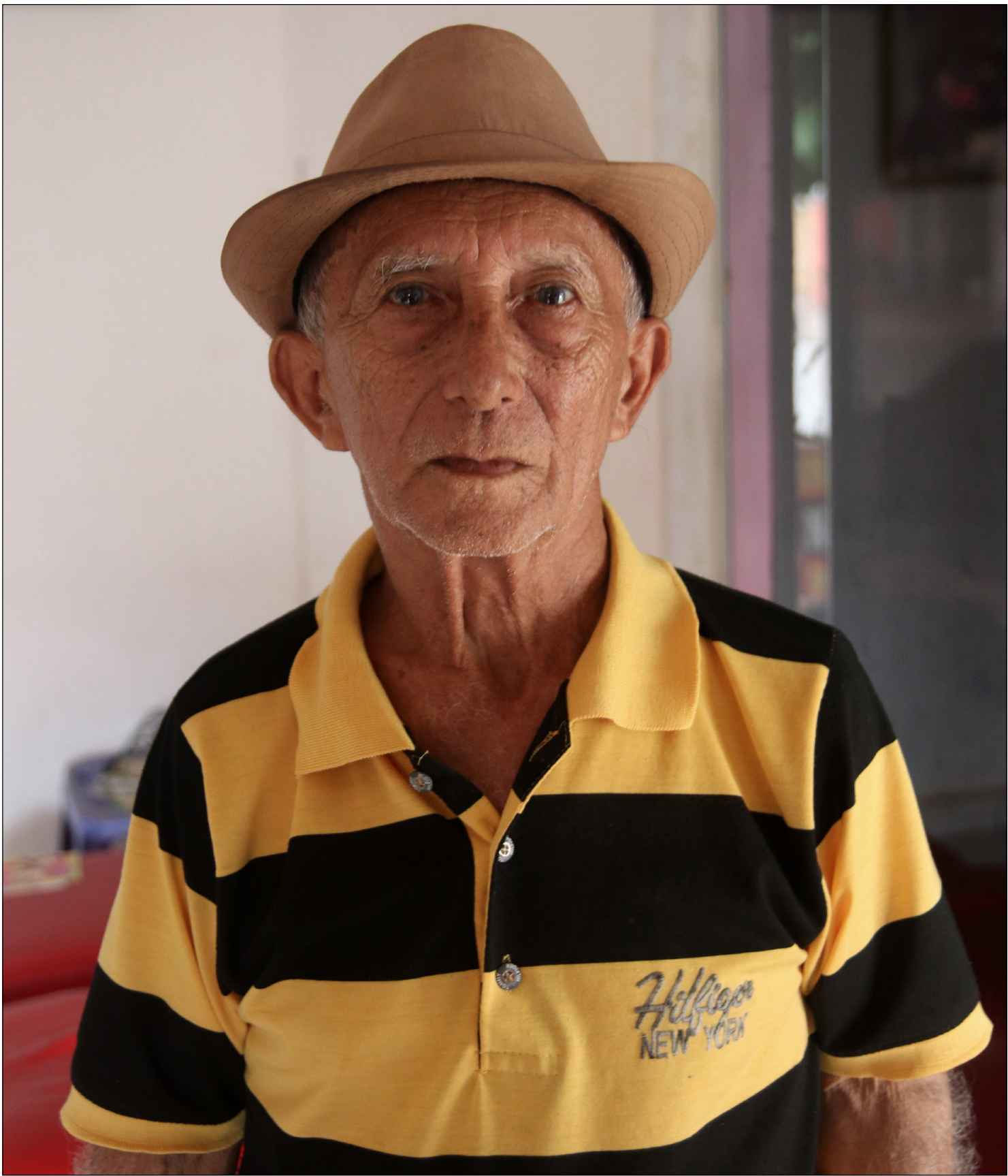

Figura 1 - Sr. Toim, 81 anos, cearense. Nascido em Frecheirinha, Ceará, veio ainda moço ao Pará para ganhar a vida. Como diz ele: "eu vim jogado aí num navio, o governo estava jogando gente naquele tempo, em 1958, por causa da seca”. Toim é analfabeto, de estatura de pouco mais de 1,50 metros, sempre trajando calça e camisa impecavelmente passadas. Ele carrega o diminutivo do nome Antônio da infância, em alusão ao seu tamanho, e foi assim que ficou conhecido no garimpo. Com emoção singular, relata a vida de homem forjado no trabalho pesado e dos sofrimentos passados durante sua trajetória, considerados vencidos por ele, sob um olhar já na velhice. Foto: Carlos Bandeira Jr. (2018). 


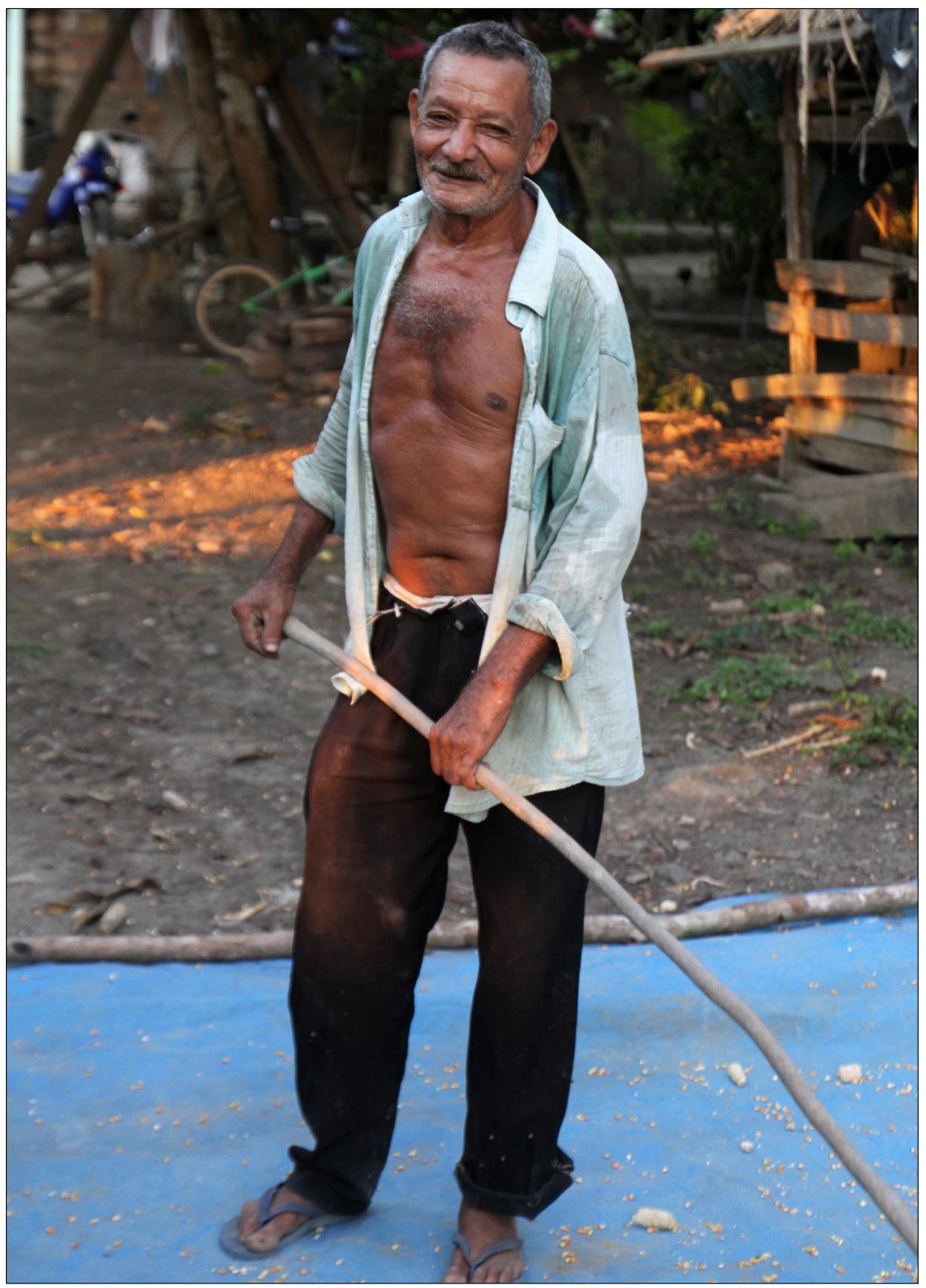

Figura 2 - João Maranhense, 76 anos, migrou ao Pará na década de 1960. Inicialmente, trabalhou com lavoura e derrubada para plantação em diversas colônias da região do baixo Tapajós. Depois de muito escutar notícias sobre garimpo, foi tentar a vida nessa atividade. Ele informou que trabalhou apanas na garimpagem manual, sem uso de bombas de água, e consegiu, na época, tirar uma boa quantidade de ouro, quase um quilo, mas gastou tudo com mulheres e bebidas nos bares da corrutela. Atualmente, é agricultor familiar e possui uma pequena propriedade localizada no planalto santareno. Foto: Carlos Bandeira Jr. (2018). 


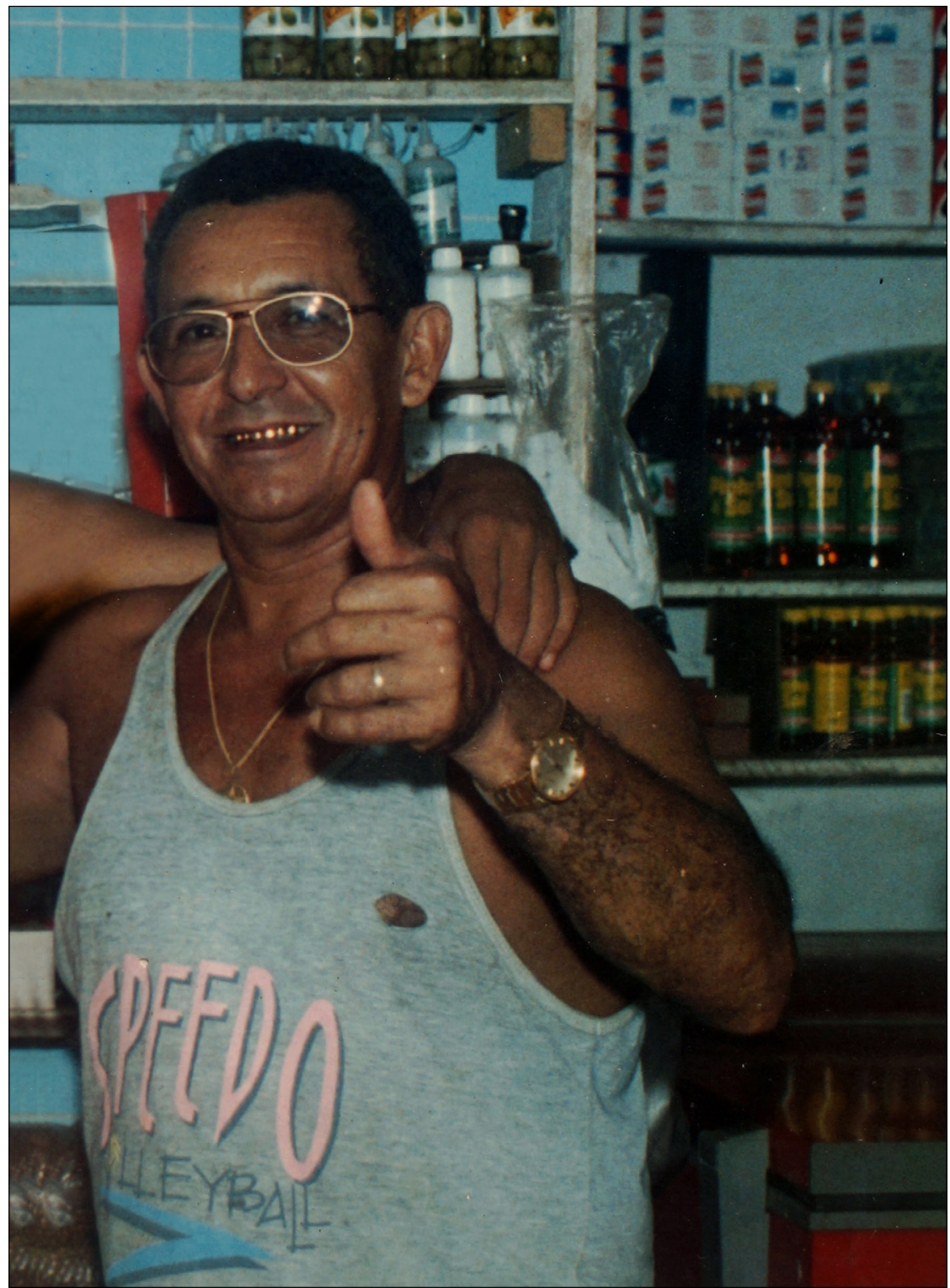

Figura 3 - Sr. Jovêncio, 73 anos, piauiense, relatou a perda dos pais ainda criança e o sofrimento passado durante a criação dada pelos tios. Conta ele que apanhava muito e tinha que trabalhar pesado no corte de lenha, o que o fez sair de casa ou "tomar conta das ventas" aos doze anos de idade. O primeiro deslocamento que realizou foi para a capital maranhense, a cidade de Imperatriz, lugar onde casou pela primeira vez. Logo depois disso, dirigiu-se para Marabá, Pará. Até esse momento da vida, sua atividade de trabalho era na lavoura e na juquira, que é uma etapa de trabalho de derrubada do mato para realizar a plantação. Trabalhava no regime de diária como peão. Não contou quanto tempo ficou em Marabá, mas que lá constituiu patrimônio, como gados, casas de aluguel e fazenda. Após a separação da primeira esposa e o casamento com a segunda, retornou ao Piauí. Relatou o insucesso de trabalho neste local e, com conhecimento mínimo sobre o garimpo, no ano de 1965, entrou por conta própria para essa atividade na Fazenda do Mamuí, no regime de trabalho manual. Atualmente, o Sr. Jovêncio vive dos proventos da aposentadoria e de aluguéis de casas que construiu ainda quando era garimpeiro. Foto: acervo pessoal. 


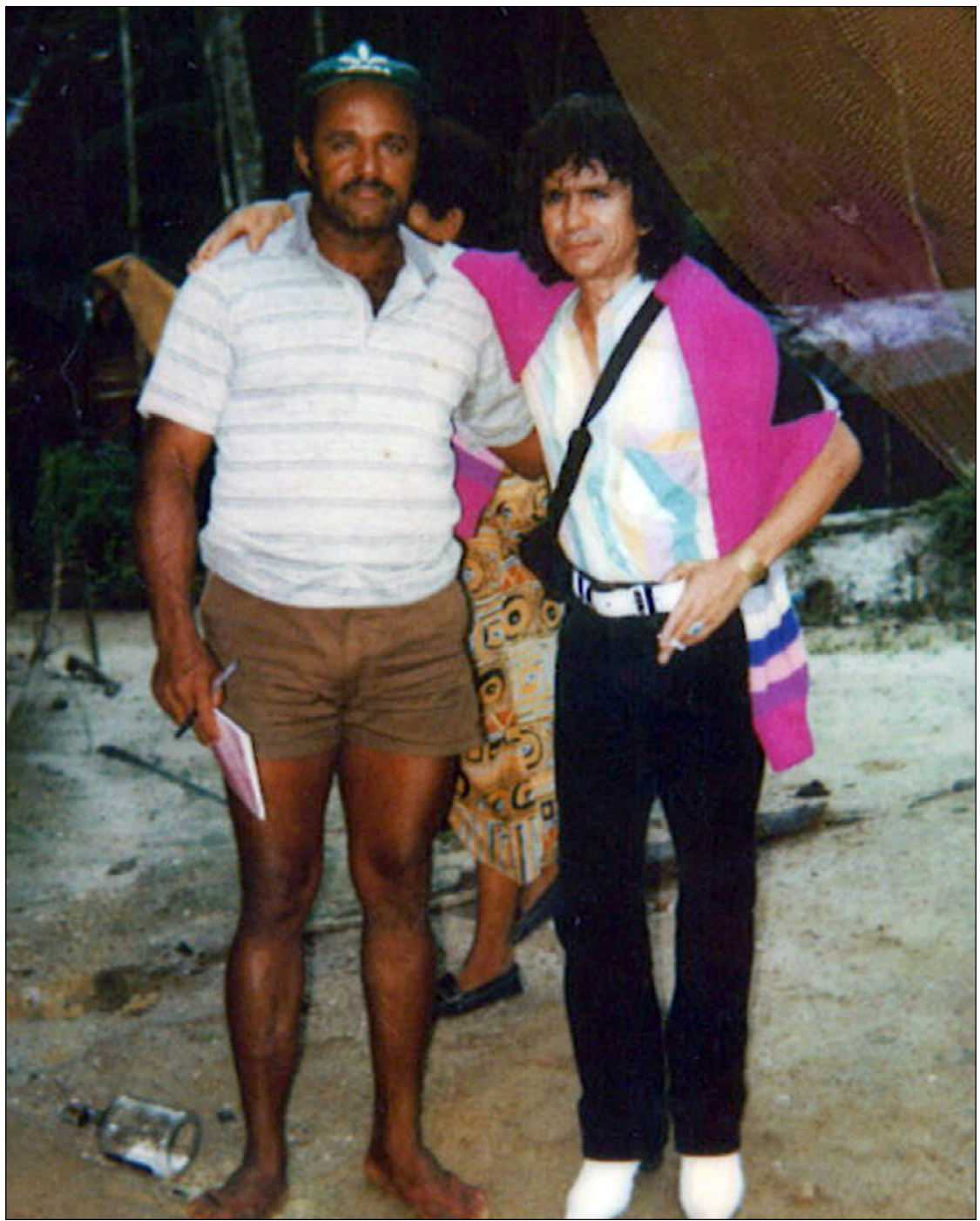

Figura 5 - Sr. José Luiz ao lado do cantor Bartô Galeno. Foto: acervo pessoal.

No toca-fita do meu carro,

Uma canção me faz lembrar você,

Acendo mais um cigarro

E procuro lhe esquecer.

Do meu lado está vazio,

Você tanta falta me faz, pois cada dia que passa

Eu te amo muito mais

Encontrei no porta-luva um lencinho

Que você esqueceu.

E num cantinho bem bordado

O seu nome junto ao meu

(Música: "No toca fita do meu carro"/Bartô Galeno) 


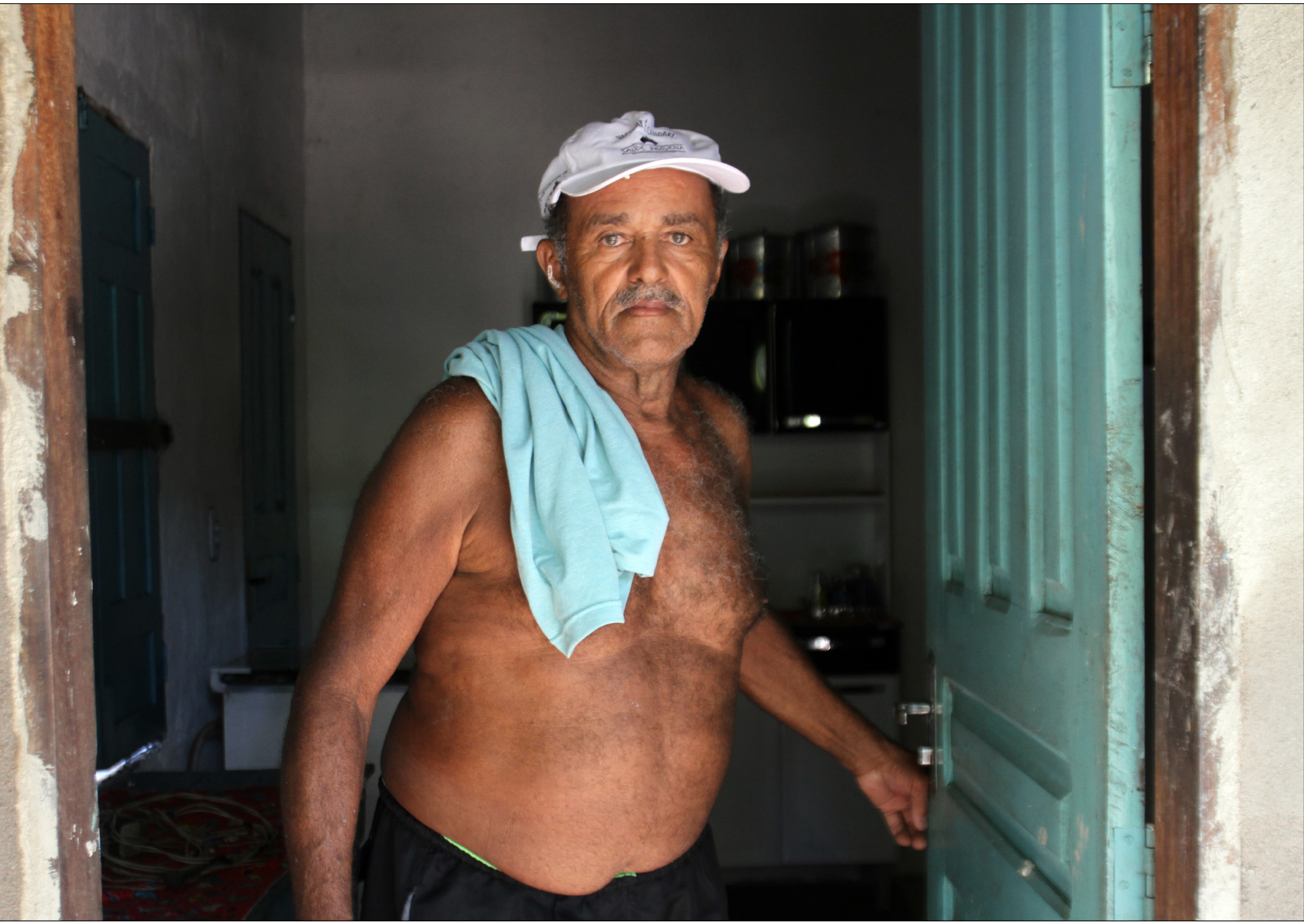

Figura 6 - Sr. Zé Luiz, 76 anos, paraense, nasceu em Santa Maria das Barreiras. Seu primeiro contato com o garimpo foi como marreteiro. Comprava mercadoria na cidade e vendia nas zonas garimpeiras. Induzido pela "fofoca" do ouro possibilitar bamburrar, veio a atuar nos barrancos no regime de trabalho manual e, com o passar do tempo, migrou para a exploração semi-mecanizada. Zé Luiz foi garimpeiro "manso" - na terminologia garimpeira, refere-se a trabalhador experiente, com amplo domínio dos saberes da atividade -, esteve em vários garimpos da região do Tapajós, como Creporizinho e Cuiú. Também chegou a garimpos das Guianas de forma clandestina, mas não permaneceu lá por muito tempo, devido à fiscalização intensa sobre a atividade nessa região. Relatou nunca ter possuído muito ouro, apesar de ter sido dono de maquinário e de uma pequena área de garimpo. Devido a prejuízo decorrente de barrancos pobres em ouro, necessitou vender seu maquinário fiado e a prestações. Ele carrega mágoa dessa negociação, pois só recebeu a primeira parcela do combinado, o que o fez ficar no "brefo" (isto é, pobre, sem dinheiro, passando necessidade), até para suprir as necessidades básicas. Para comer, ele fazia um "reco", que é reprocessar o curimã, a terra que já tinha sido explorada em momento anterior. Dessa ação garantia uma, duas gramas, o que dava para sobreviver de maneira precária. Atualmente, Zé Luiz vive em uma pequena casa localizada em um bairro periférico de Santarém e sustenta-se da aposentadoria e de sua pequena roça de legumes e verduras, que cuida com imenso carinho. Na Figura 5, ele está ao lado do cantor Bartô Galeno no garimpo do Cuiú. No auge financeiro dos garimpos do Tapajós, era comum artistas de renome nacional realizarem shows nas corrutelas garimpeiras. Foto: acervo pessoal 


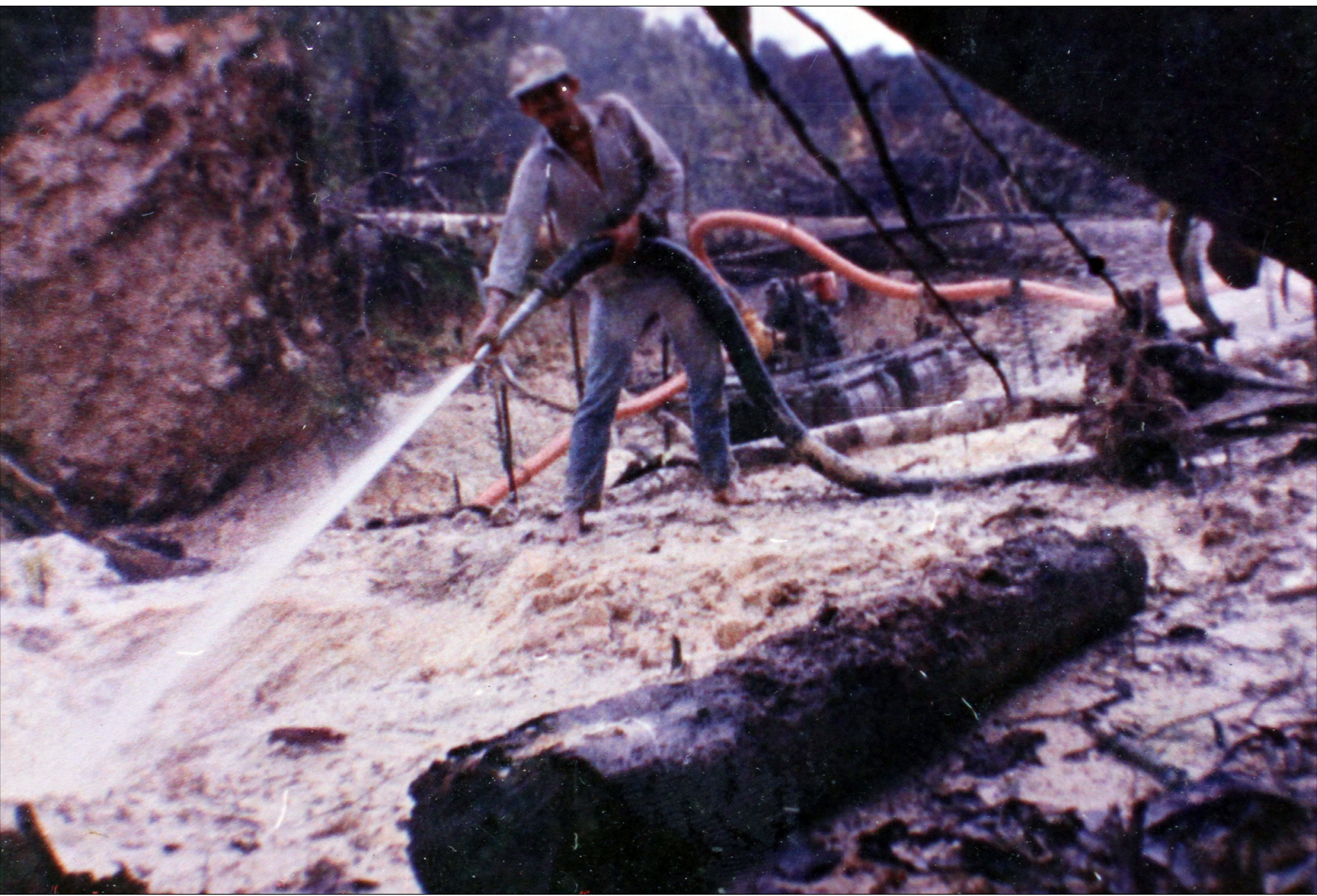

Figura 7 - Paulo Afonso operando a mangueira bico-jato. Na imagem, o garimpeiro trabalha como jateiro, que tem a função de realizar a derrubada das paredes do barranco e encaminhar a lama com ouro por meio de um canal até um poço aberto pelos trabalhadores, para que esse material seja puxado pela maraca até o topo do barranco, onde fica a "lontona", ou caixa, equipamento responsável por agarrar o ouro misturado à lama. Foto: acervo pessoal.

1 Maquinária artesanal confeccionada pelos próprios garimpeiros com madeira retirada da floresta. O garimpeiro Luiz detalha o equipamento: "A lontona é tipo uma porta, só que ela é maior que uma porta, ela dá umas três portas de comprimento, aí a gente bota uma tábua assim de lado, baixinho, na base de uns $10 \mathrm{~cm}$. Ela é calafetada porque não pode varar água de jeito nenhum, se não o ouro vai embora. A gente calafeta com mangueira, pega a mangueira, queima e bota nas brechas da tábua. Quando acabar, bota a sarrapilha e depois um carpete de $2 \mathrm{~m}$, perto de onde vai cair a bica com o cascalho. O carpete é da largura dela. Entarisca (ação de pôr talas de um lado a outro do equipamento para que a água desça em cascata), bota muito azougue ali. Uma base de umas $200 \mathrm{~g}$ de azougue para poder o ouro, quando bater o azougue, pegar o ouro. O azougue é para segurar o ouro” (Sr. Zé Luiz, comunicação pessoal, out. 2017). 


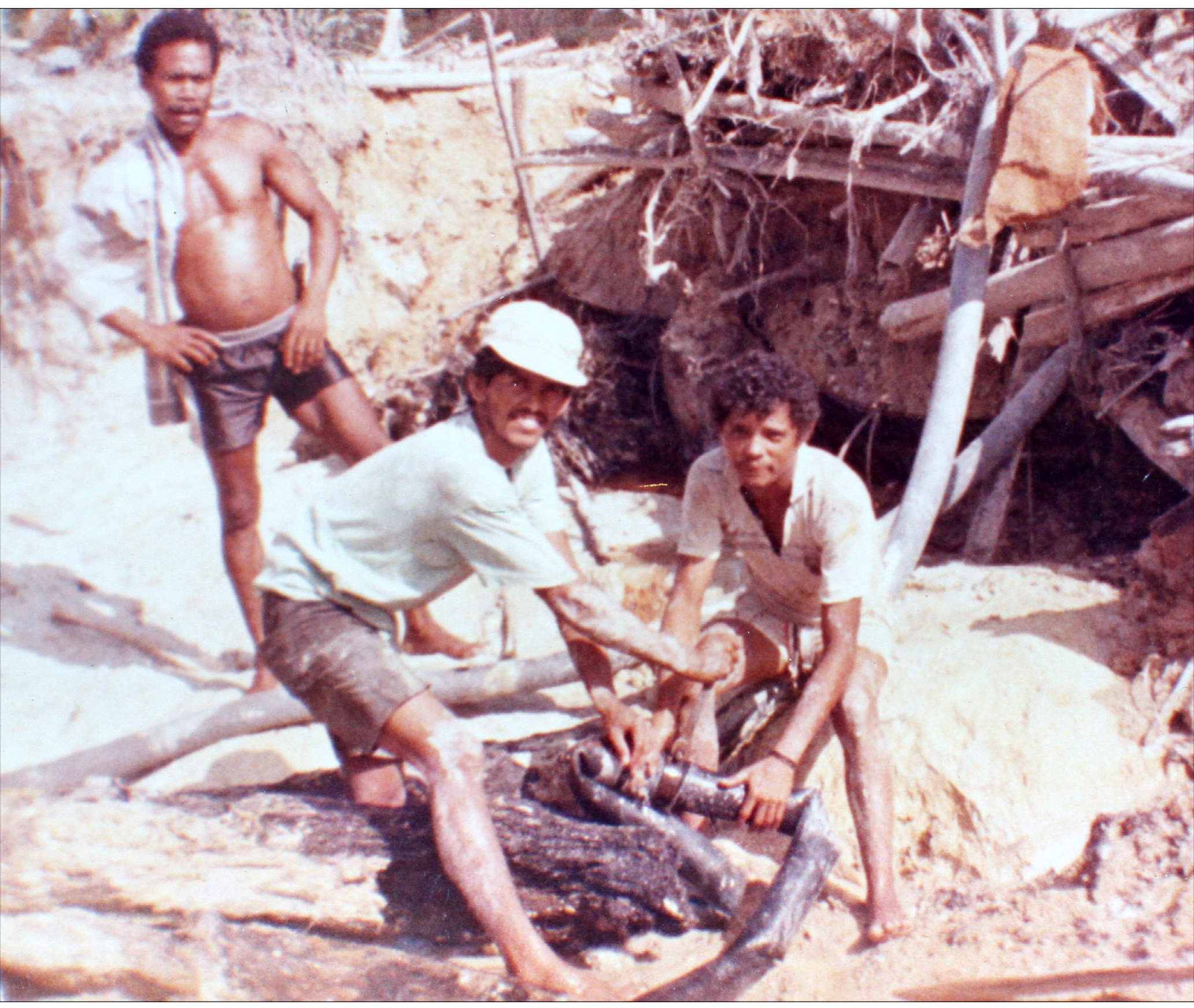

Figura 8 - Paulo Afonso e parceiros de trabalho consertando mangueira de absorção do cascalho de ouro. Foto: acervo pessoal. 


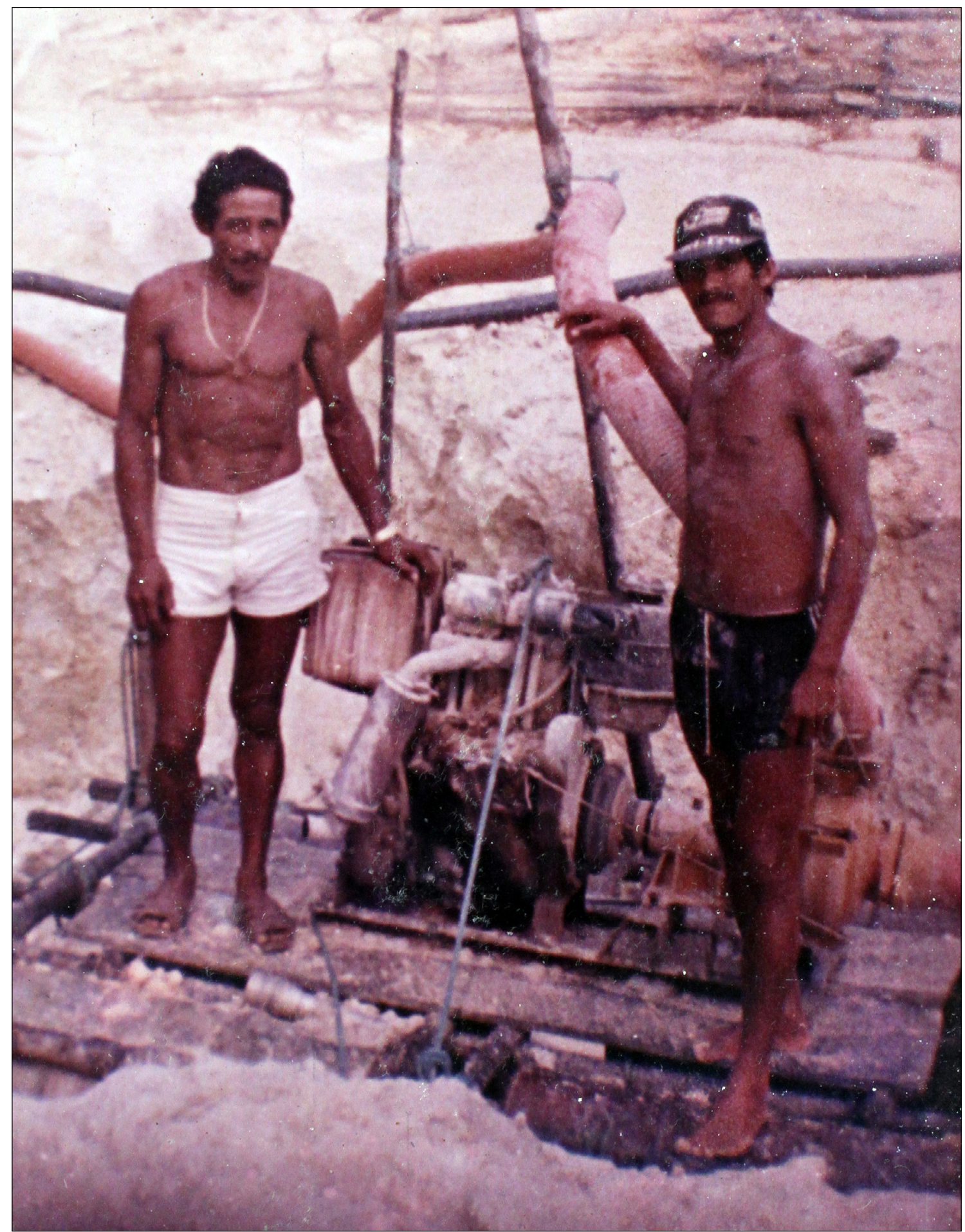

Figura 9 - Paulo Afonso e parceiro sobre o poço da maraca, a bomba de sucção da lama com o ouro. Foto: acervo pessoal. 


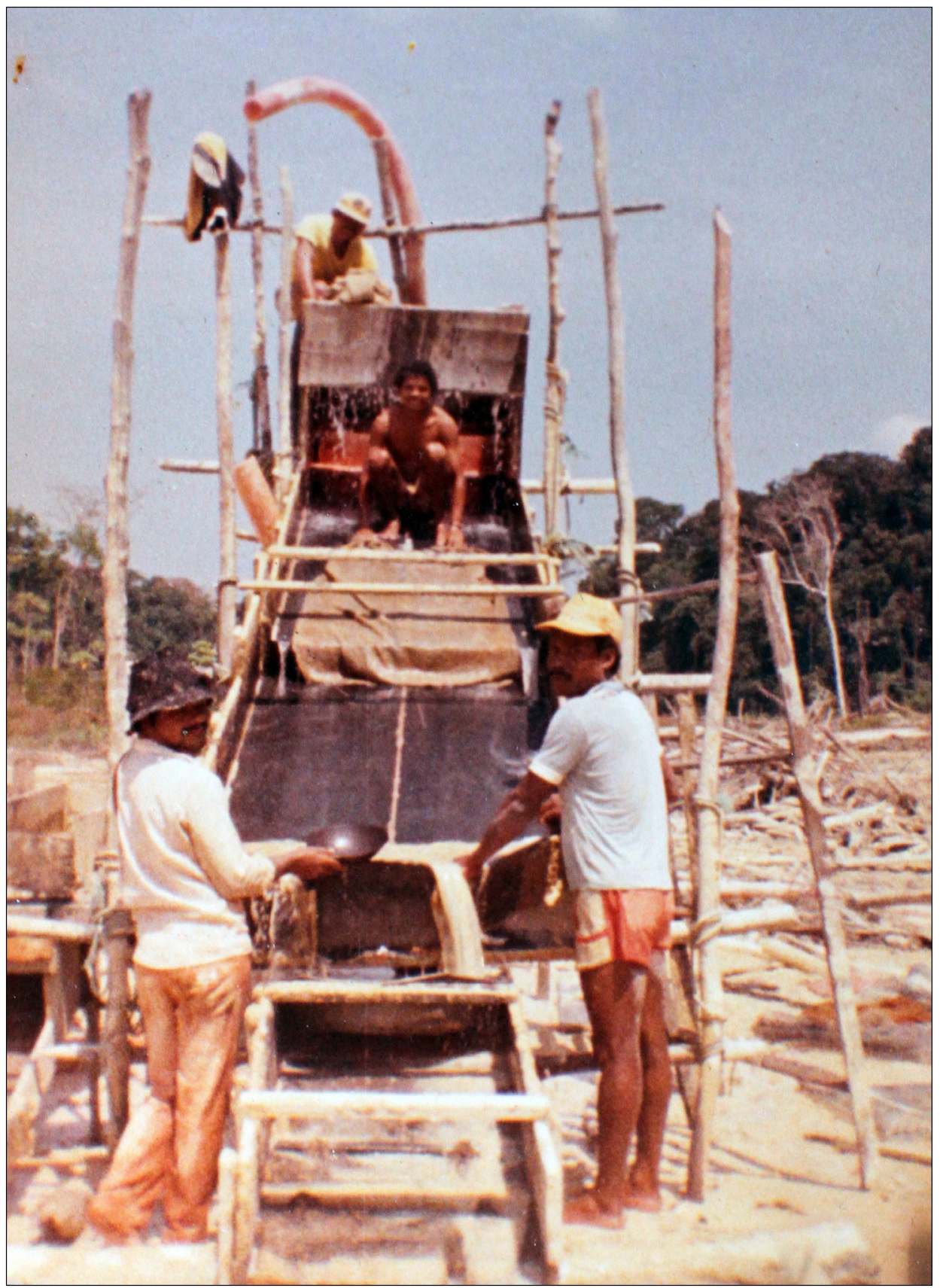

Figura 10 - Despescagem da caixa/"lontona", uma das finais para obtenção do ouro. Após o processamento na "lontona", passa-se para esse momento, que é a retirada do carpete com ouro, como se vê na imagem. Esse carpete é lavado com sabão em pó dentro de baldes, sendo comumente utilizados carotes de óleo ou coxos. Os coxos são recipientes cilíndricos feitos de troncos de árvores. O ouro com terra cai dentro dos baldes. Note-se que está misturado ao azougue, que é a nomenclatura garimpeira para o metal pesado mercúrio, utilizado para segurar o ouro que passa junto com outros detritos pela "lontona". Esses baldes são levados para um local próximo a um igarapé, para que o material seja "bateiado", isto é, para que seja feita a limpeza do ouro por meio do equipamento bateia, que é um disco cônico de metal. Foto: acervo pessoal. 